\title{
Stroke Burden and Stroke Services in Bangladesh
}

\author{
Narayanaswamy Venketasubramanian ${ }^{b}$ Muzharul Mannan ${ }^{a}$ \\ aDepartment of Neurology, Institute for Paediatric Neurodisorder and Autism, Bangabandhu Sheikh Mujib Medical

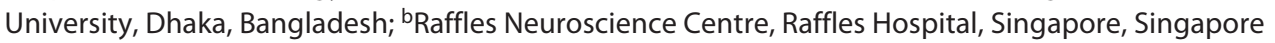

Bangladesh, with a population of 165.6 million people, is located in the northwest region of South Asia, bordered on the west, north, and east by India, southeast by Myanmar, and south by the Bay of Bengal [1]. The per-capita income is USD 1,909 , poverty rate is $20.5 \%$, literacy ( $7+$ years) is $73.2 \%$, and life expectancy is 72.3 years; $74 \%$ live in rural areas.

Stroke is a major cause of death and disability in the region, with an age- and sex-standardized mortality rate of 54.8 per 100,000 and disability-adjusted life years lost of 888.1 per 100,000 in Bangladesh [2]. The prevalence of stroke at approximately $1-2 \%$ of those aged over 20 years [3] is similar in males and females, and urban and rural areas [4], but increases with age such that the ratio of infarction to hemorrhage is 2.91 in the community [5]. Stroke incidence has not been studied in adequate epidemiological studies. In a large multicenter hospital study, $72 \%$ had ischemic stroke, and the frequency of hypertension, smoking, diabetes mellitus, ischemic heart disease, and dyslipidemia was $58 \%, 45 \%, 23 \%, 17 \%$, and $5 \%$, respectively [6]; these are not from population-based studies. Small-vessel "lacunar" disease was the most common type of ischemic stroke, and there is a clear seasonal variation in the frequency of hemorrhagic stroke $[7,8]$. The high stroke mortality among Bangladeshi populations may be due to the high frequency of the conventional atherosclerotic risk factors, especially of hypertension and diabetes mellitus [9]; there is a strong belief over the importance of betel nut chewing, squatting and straining during defecation, chron-

\section{karger@karger.com www.karger.com/cee \\ Karger"}

(c) 2021 The Author(s)

Published by S. Karger AG, Basel

GOPEN ACCESS ic infection, vitamin D deficiency, and the combined effect of smoking and tobacco chewing [10]. Stroke mortality might be related to stroke severity, delayed diagnosis, and stroke care gaps discussed further below.

Medical services are free in the community [11]. Community clinics are available at villages at ward levels, while small hospital services are located at the union and upazila levels. Secondary level care is provided at district hospitals; tertiary level care is provided at medical college hospitals and super-specialty hospitals.

There are 2,213 hospitals with 45,723 registered physicians, but only 160 trained neurologists through training programs only provided at Dhaka Medical College (DMC) and Bangabandhu Sheikh Mujib Medical University (BSMMU). There are 2,300 technologists operating 250 CT scans and 80 MRIs in Bangladesh.

Acute care for stroke patients is available in 2 government and 5 private hospitals, all situated in Dhaka, the capital city, while subacute care provided by neurologists is available in 23 government hospitals located in most parts of the country and 7 private hospitals. Stroke is the most common condition among neurology in-patients (48\%) [12] and out-patients (24\%) [13].

The Bangladesh Rehabilitation Assistance Committee (BRAC), a nongovernmental organization (NGO), provides stroke rehabilitation services to patients who cannot afford treatment and conducts education programs to raise awareness about the signs and symptoms of stroke [14]. Another NGO, the Centre for the Rehabilitation of 
Fig. 1. World Stroke Day 2018, co-organized by the SNB and BSMMU. Reprinted with kind permission of the SNB. SNB, Society of Neurologists of Bangladesh; BSMMU, Bangabandhu Sheikh Mujib Medical University.

Fig. 2. Attendees at a continuing medical education program. Reprinted with kind permission of the SNB. SNB, Society of Neurologists of Bangladesh.
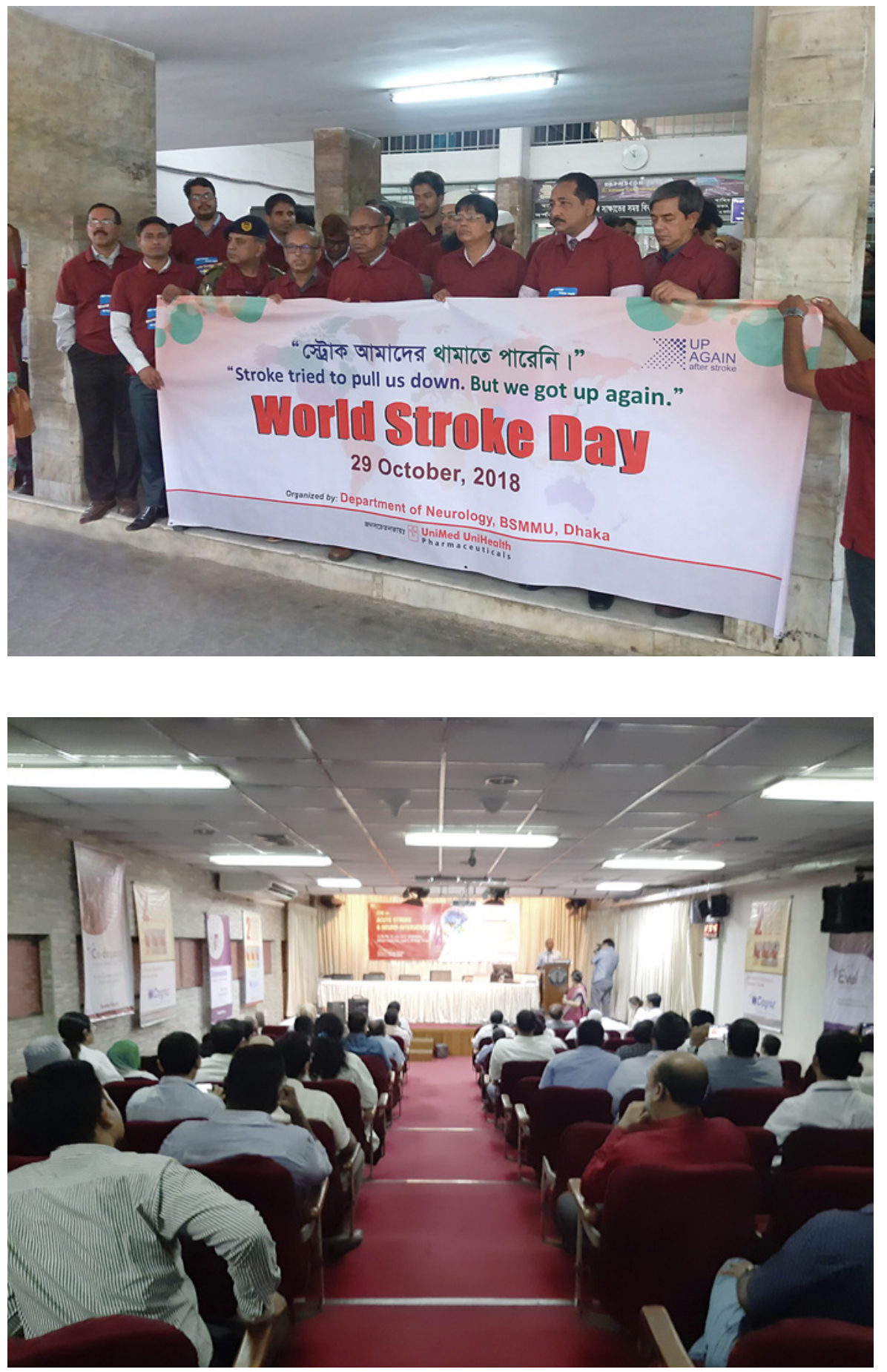

the Paralysed (CRP), provides physiotherapy, speech and language therapy, and occupational therapies to stroke patients, as well as educating the public on the symptoms of stroke [15]. The few other stroke care services are mostly based in Dhaka, with in-patient beds in government and private resources combined, such as the Na- tional Institute of Neurosciences \& Hospital, BSMMU; Bangladesh Institute of Research and Rehabilitation for Diabetes, Endocrine and Metabolic Disorders (BIRDEM); Holy Family Medical Collage Hospital; DMC Hospital; and Bangladesh Medical College Hospital. Rehabilitation costs approximately USD 328 per month 
[16], and early rehabilitation is helpful in certain populations [17].

There are a few instances where lay volunteers provide community service for stroke patients, particularly in assisting family members in the provision of care for those who are disabled and infirm.

The main primary preventive approaches being promoted during public education involve maintaining a healthy lifestyle, blood pressure control, not smoking (and smoking cessation for smokers), being physically active, and a healthy diet characterized by adequate fruit and vegetable intake, and reduced intake of salt and trans-fats.

The Society of Neurologists of Bangladesh (SNB) at present organizes all stroke-related training, awareness programs, and support programs [18] (Fig. 1, 2). There are several private nonmedical support groups established by therapists or social workers such as the Bangladesh Stroke Association (BSA) [19]. This stroke support group supports patients across the country. Their main motto is that "No stroke survivor shall die untreated and un-rehabilitated even if he/she is poor." BSA started its operations in early 2014.

More needs to be done for stroke care in Bangladesh. More stroke physicians and rehabilitation services, especially in the rural areas, are needed [20]. Community resources need to be strengthened for stroke survivors. Ef- fective public education programs aimed at stroke prevention must continue. With these measures, the burden of stroke in Bangladesh can be reduced.

\section{Statement of Ethics}

The Society of Neurologist of Bangladesh (SNB) gave the authors the permission to use the photographs of the celebration of World Stroke Day all around Bangladesh in different institutions under our supervision and/or our member's supervision. All our members very willingly gave their verbal permission to use their photographs along with the study "Stroke Burden and Stroke Services in Bangladesh." SNB will bear all responsibility if there are any future disputes regarding the use of the photos.

\section{Conflict of Interest Statement}

The authors have no conflicts of interest to declare.

\section{Funding Sources}

The authors did not receive any funding.

\section{Author Contributions}

M.M. and N.V. both conceptualized the study, wrote the manuscript, approved the final manuscript.

\section{References}

1 Bangladesh National Portal. Available from: https: //bangladesh.gov.bd/index.php Accessed 2020 December 3 .

2 Venketasubramanian N, Yoon BW, Pandian J, Navarro JC. Stroke epidemiology in South, East, and South-East Asia: a review. J Stroke. 2017;19:286-94.

3 Khanam F, Hossain MB, Mistry SK, Afsana K, Rahman M. Prevalence and risk factors of cardiovascular diseases among Bangladeshi adults: findings from a cross-sectional study. J Epidemiol Glob Health. 2019;9: 176-84.

4 Chowdhury MZI, Haque MA, Farhana Z, Anik AM, Chowdhury AH, Haque SM, et al. Prevalence of cardiovascular disease among Bangladeshi adult population: a systematic review and meta-analysis of the studies. Vasc Health Risk Manag. 2018;14:165-81.

5 Saha UK, Alam MB, Rahman AKMF, Hussain AHME, Mashreky SR, Mandal G, et al. Epidemiology of stroke: findings from a community-based survey in rural Bangladesh. Public Health. 2018;160:26-32.

6 Mohammad QD, Habib M, Mondal BA, Chowdhury RN, Hasan MH, Hoque MA, et al. Stroke in Bangladeshi patients and risk factor. Mymensingh Med J. 2014;23:520-9.
7 Bhowmik NB, Abbas A, Saifuddin M, Islam MR, Habib R, Rahman A, et al. Ischemic strokes: observations from a hospital based stroke registry in Bangladesh. Stroke Res Treat. 2016;2016:5610797.

8 Miah AH, Sutradhar SR, Ahmed S, Bhattacharjee M, Alam MK, Bari MA, et al. Seasonal variation in types of stroke and its common risk factors. Mymensingh Med J. 2012; 21:13-20.

9 Mateen FJ, Carone M, Alam N, Streatfield PK, Black RE. A population-based case-control study of 1250 stroke deaths in rural Bangladesh. Eur J Neurol. 2012;19:999-1006.

10 Bhopal R, Rahemtulla T, Sheikh A. Persistent high stroke mortality in Bangladeshi populations. BMJ. 2005;331:1096-7.

11 Available from: https://dghs.gov.bd/images/ docs/Publicaations/HealthBulletin2017Final13_01_2018.pdf.

12 Chowdhury RN, Hasan AT, Ur Rahman Y, Khan SI, Hussain AR, Ahsan S. Pattern of neurological disease seen among patients admitted in tertiary care hospital. BMC Res Notes. 2014;7:202.

13 Uddin MS, Al Mamun A, Asaduzzaman M, Hosn F, Abu Sufian M, Takeda S, et al. Spectrum of disease and prescription pattern for outpatients with neurological disorders: an empirical pilot study in Bangladesh. Ann Neurosci. 2018;25:25-37.

14 Bangladesh Rehabilitation Assistance Committee. Available from: www.brac.net. Accessed 2020 December 3.

15 Centre for the Rehabilitation of the Paralyzed (CRP). Available from: www.crp-bangladesh. org. Accessed 2020 December 3.

16 Mamin FA, Islam MS, Rumana FS, Faruqui F. Profile of stroke patients treated at a rehabilitation centre in Bangladesh. BMC Res Notes. 2017; 10:520.

17 Nessa J, Khaleque MA, Begum S, Ahmed AH, Islam S, Afsan M. Rehabilitation of Stroke Patients-Effects of Early Intervention of Physical Therapy on Functional Outcome. Bangladesh J Anat. 2009;7:62-7.

18 Society of Neurologists of Bangladesh. Available from: www.snb.org.bd. Accessed 2020 December 3.

19 Bangladesh Stroke Association. Available from: www.stroke.autismbd.com. Accessed 2020 December 3.

20 Islam MN, Moniruzzaman M, Khalil MI, Basri R, Alam MK, Loo KW, et al. Burden of stroke in Bangladesh. Int J Stroke. 2013;8: 211-3. 